\title{
The Effect of Group Counseling Based on Health Belief Model on Nutritional Behavior of Pregnant Women with Overweight: a Randomized Controlled Trial
}

\section{Sahar Saadatnia ${ }^{1}$, Farzaneh Soltani ${ }^{2}$, Amir Saber ${ }^{3}$, Farideh Kazemi ${ }^{4 *}$}

1. MSc, Department of Midwifery Counseling, School of Nursing and Midwifery, Hamadan University of Medical Sciences, Hamadan, Iran

2. Associate Professor, Department of Reproductive Health, Mother and Child Care Research Center, Hamadan University of Medical Sciences, Hamadan, Iran

3. Assistant Professor, Department of Nutritional Sciences, Department of Nutritional Sciences, School of Nutritional Sciences and Food Technology, Kermanshah University of Medical Sciences, Kermanshah, Iran

4. PhD, Department of Reproductive Health, Mother and Child Care Research Center, Department of Midwifery, School of Nursing and Midwifery, Hamadan University of Medical Sciences, Hamadan, Iran

\section{Article Info \\ Received: 2020/07/29; \\ Accepted: 2020/08/14; \\ Published Online: 2020/11/28 \\ 10.30699/sjhnmf.29.2.102}

Original Article

Use your device to scan and read the article online

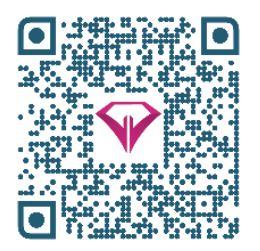

\section{ABSTRACT}

Introduction: Overweight and obesity are a significant challenge in pregnancy care. This study was conducted to investigate the effect of group counseling based on health belief model on nutritional behavior of overweight pregnant women referred to Kermanshah health centers.

Methods: This clinical trial was performed in 2018 on 90 pregnant women in Kermanshah. Among the comprehensive health centers, 4 centers were randomly selected for intervention and 4 centers for the control group. Then 4 sessions of group counseling program prepared for the intervention groups were performed for one month. The content of the counseling included nutrition counseling and familiarity with the food pyramid and principles of proper nutrition, increasing sensitivity to obesity and its complications, understanding the severity of the obesity problem, understanding the obstacles and benefits of following a proper diet and increasing selfefficacy and ultimately achieving healthy eating behavior. The data collection tool was a researcher-made questionnaire including demographic and midwifery information, health belief model constructs, knowledge and nutritional behavior questionnaire. Data were analyzed using SPSS 16. Significance level was considered less than 0.05 .

Results: The mean age of participants in the intervention group was 24.91(6.19) and, in the control, group was 27.53(5.60). After controlling the effect of pre-test scores on the constructs of knowledge, perceived susceptibility, perceived severity, perceived benefits, perceived barriers, self-efficacy and nutritional behavior, the results showed a significant increase after the intervention, in the mean scores of the intervention group $(P=0.001)$.

Conclusion: The findings of this study showed the effectiveness of counseling based on the health belief model in promoting the nutritional behavior of pregnant women with high body mass index. Researchers in this study recommend counseling interventions based on this model. Therefore, the implementation of counseling intervention based on the structures of the health belief model can play an effective role in improving the nutritional behavior patterns of pregnant women.

Keywords: Consulting ‘ Health Belief Model ‘ Nutritional behavior ‘ Overweight
Corresponding Information:

Farideh Kazemi, PhD, Department of Reproductive Health, Mother and Child Care Research Center, Department of Midwifery, School of Nursing and Midwifery, Hamadan University of Medical Sciences, Hamadan, Iran. Email: faridehkazemi21@yahoo.com

Copyright $(2021$, This is an original open-access article distributed under the terms of the Creative Commons Attribution-noncommercial 4.0 International License which permits copy and redistribution of the material just in noncommercial usages with proper citation.

How to Cite This Article:

Saadatnia S, Soltani F, Saber A, Kazemi F. The Effect of Group Counseling Based on Health Belief Model on Nutritional Behavior of Pregnant Women with Overweight: a Randomized Controlled Trial. Avicenna J Nurs Midwifery Care. 2021; 29 (2) :101-112 
تأثير مشاورة گروهى مبتنىبر مدل اعتقاد بهداشتى بر رفتار تغذيلاى زنان باردار داراى اضافهوزن: يك كار آزمايى كنترلشدهُ تصادفى

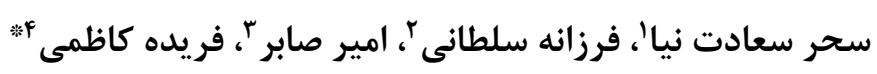

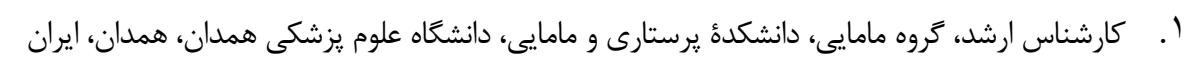

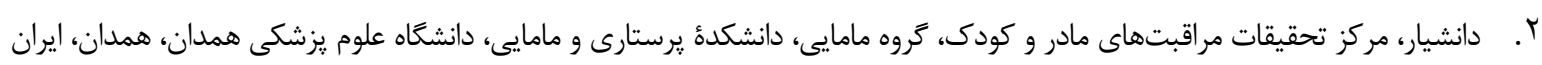

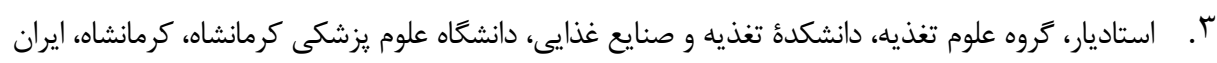

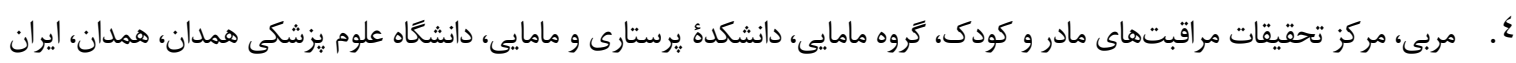

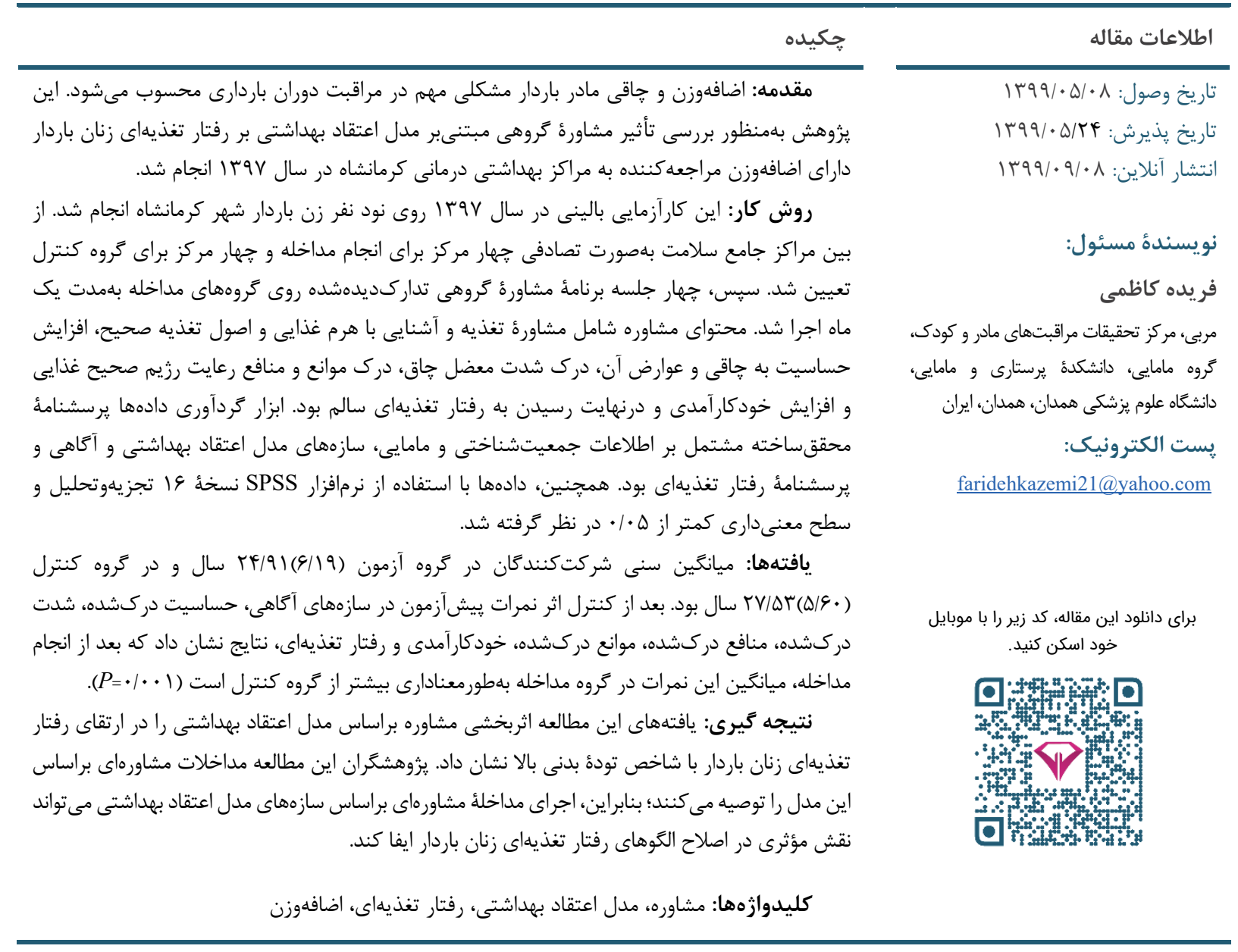

مقدمه

افراد به ميزان زيادى به دريافت موادغذايى و ساختار تغذيهاى

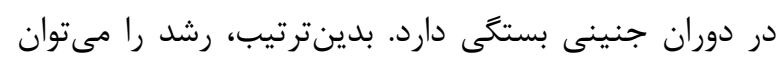

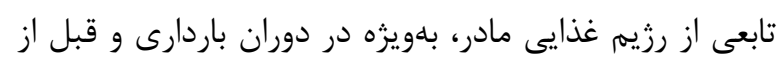

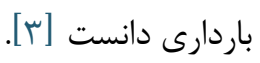
تغيير سبك زندكى بهسمت صنعتىشدن همراه باه با تغيير

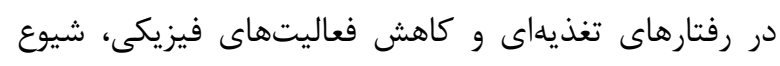

تغذئُ دوران باردارى نقش مهمى در سلامت مادر و جنين

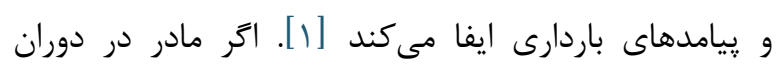

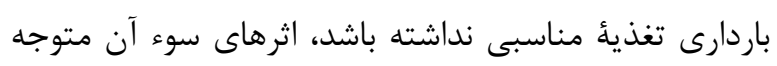

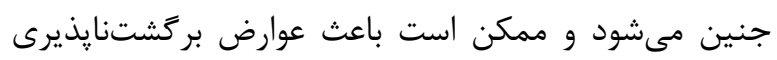

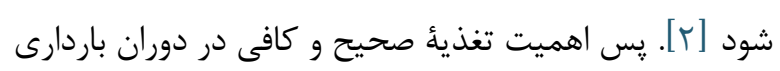

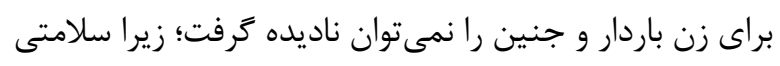


كيلوكرم براى شاخص تودة بدنى / / T تا وץ (اضافهوزن) و

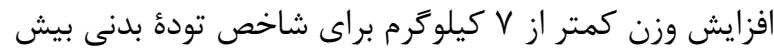

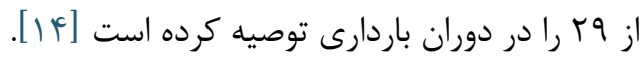

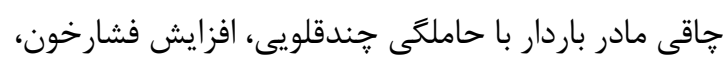
يرهاكلاميسى، اكلاميسى، باردارنشدن، ديابت باردارى، حوادث

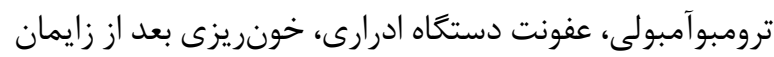

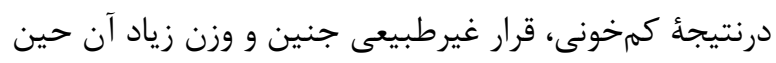

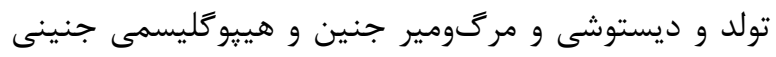

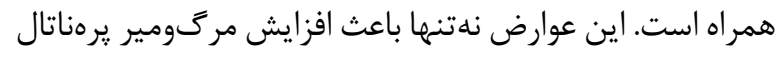

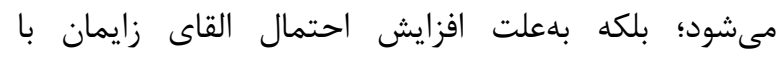

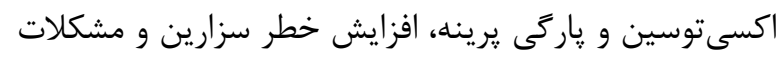

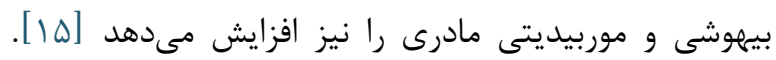

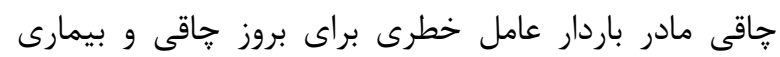

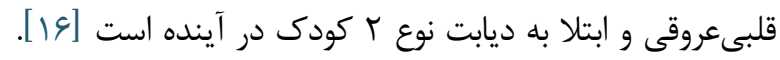

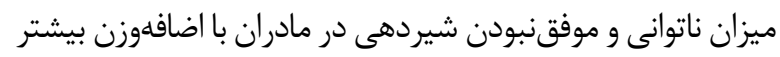

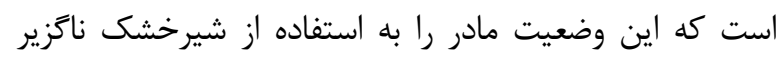

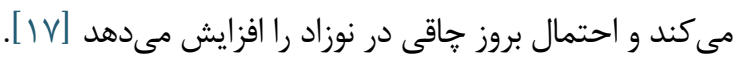

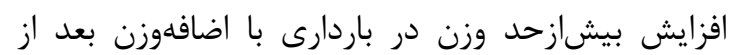

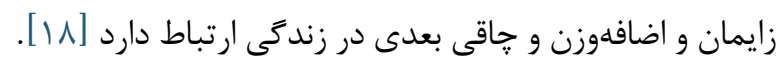

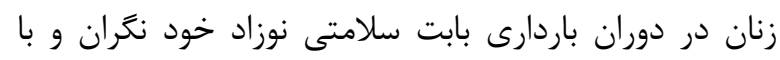

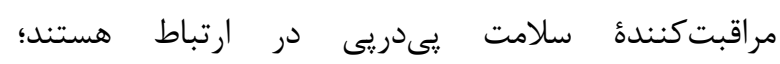

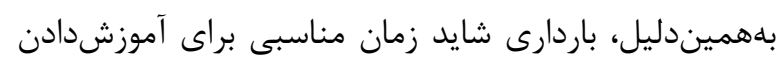

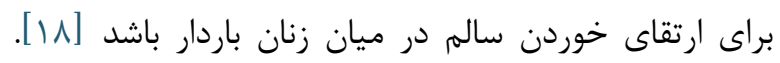

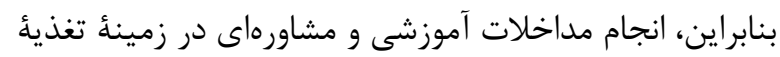
دوران باردارى براى مادران باردار ضرورى است و باعث افزايش

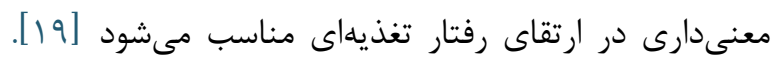
بدينمنظور، محققان از مدلها براى تغيير رفتار كمكى إنى

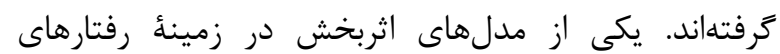

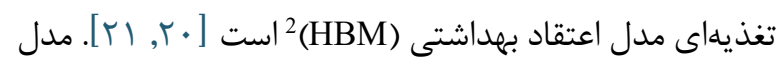

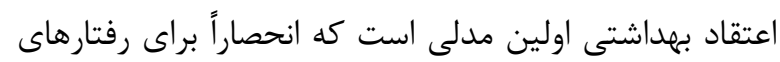

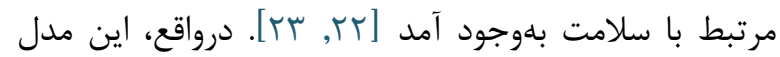

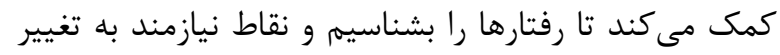

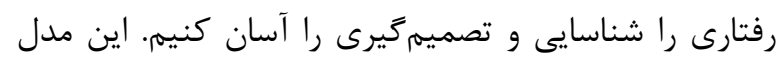

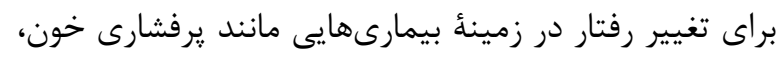

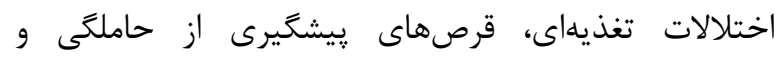

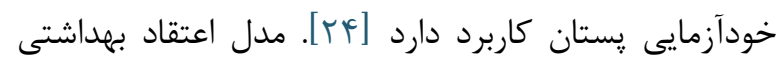

\footnotetext{
${ }^{2}$ Health Belief Model
}

جاقى را در اجتماعات افزايش داده است و تقريباً تمامى إماف

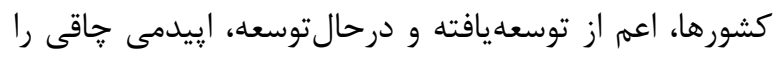

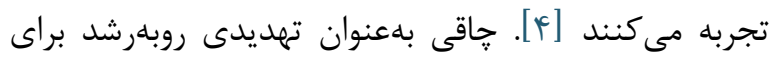

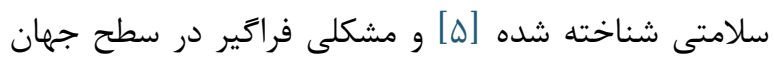

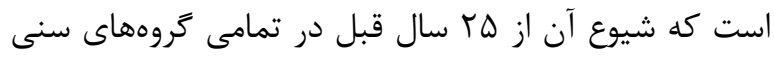

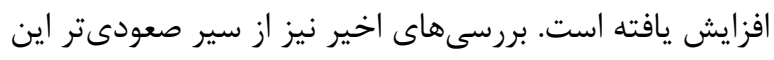

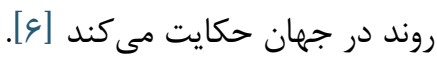

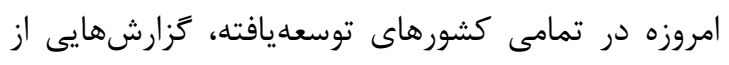
افزايش شيوع جاقى و اضافهوزن زنان سنين بارئ بارورى ارائه

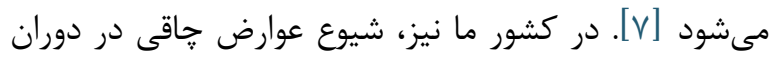

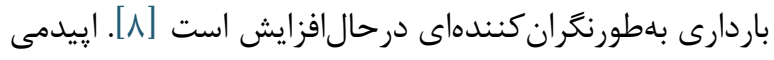

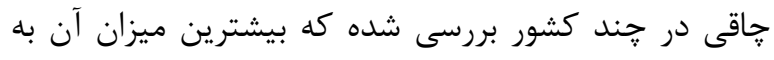
Pacific Islands بهطوركلى، در ارويا و شمال آمريكا شيوع خاقى زياد است؛ درحالى كه در آفريقا و خاورميانه، شيوع در كشورهاى كوناكون متفاوت است [9]. برآوردهاى انجامشده در مطالعهُ قند و ليييد تهران، حاكى آنى

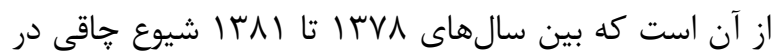

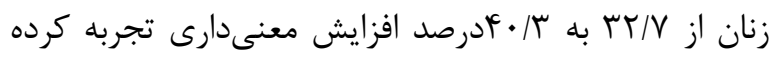

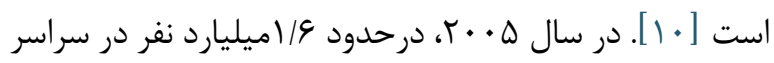

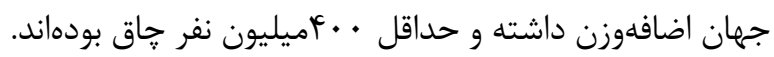

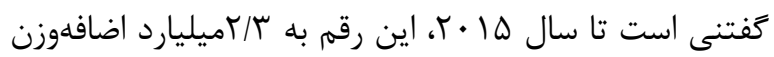

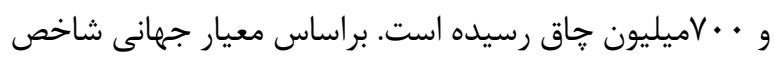

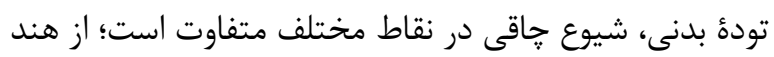

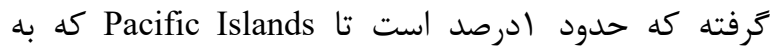

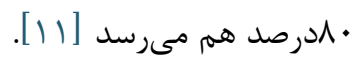
افزايش وزن زنان باردار از شاخصهاى مارس معتبر تغذيه است

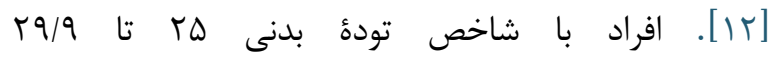

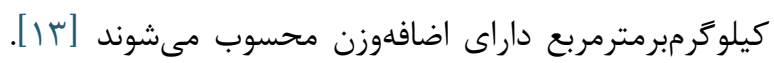

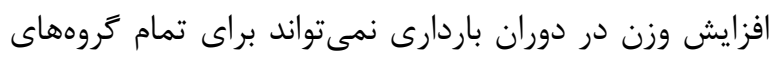

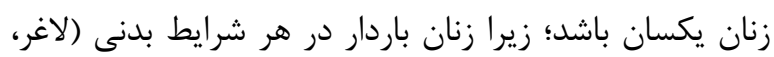

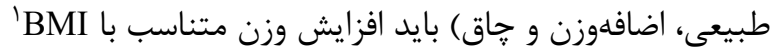

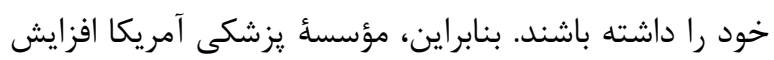

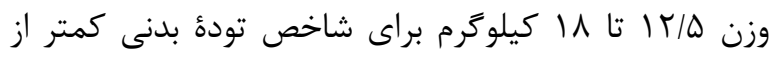

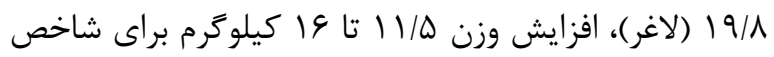

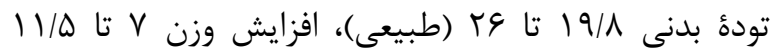

${ }^{1}$ Body Mass Index

$$
\text { مجله مراقبت يُرستارى و مامايى ابنسينا }
$$


نمونهَيرى تصادفى ساده بود و بدينمنظور از بين الب مراكز

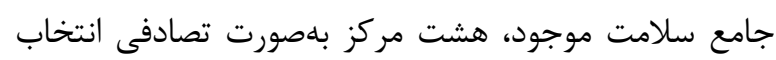

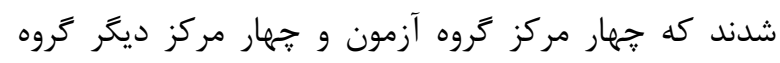

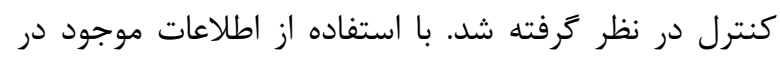

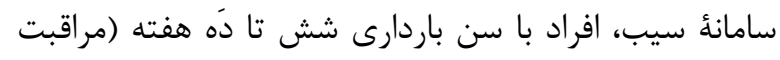

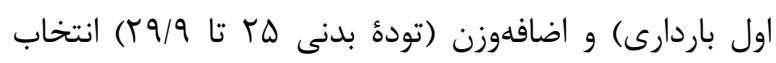

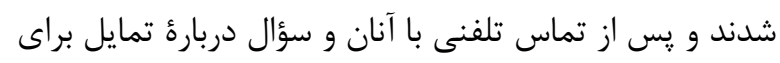

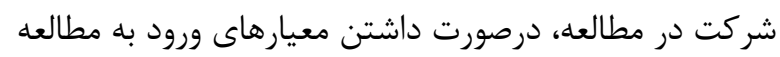

دعوت شدند.

معيارهاى ورود به مطالعه باردارى تكقلو، داشتن سواد

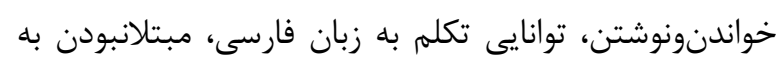

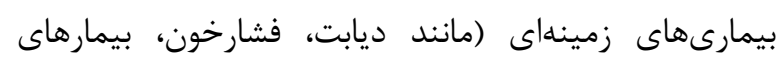

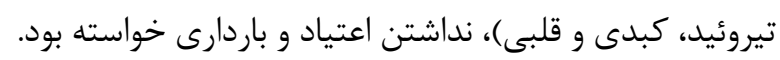

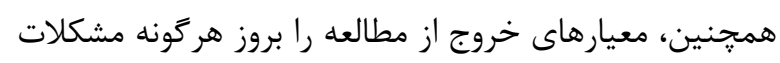

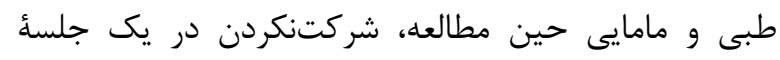

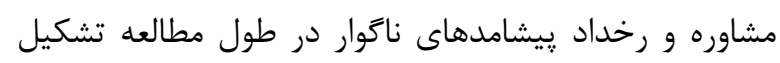

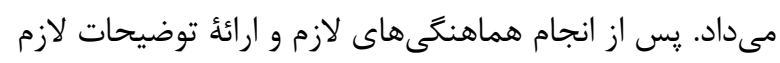

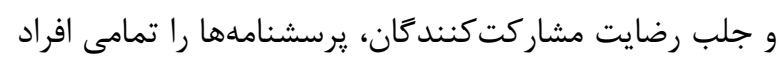

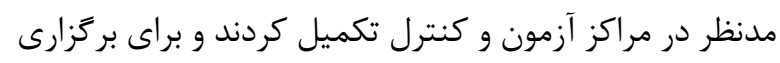

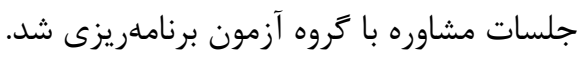

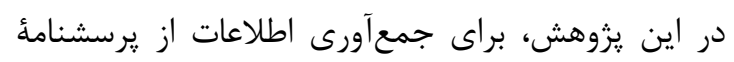

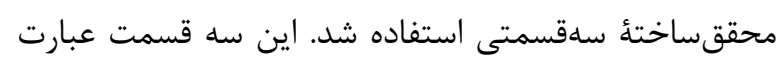
بودند از:

ا. بخش اول شامل مشخصات جمعيتشناختى و مامايى

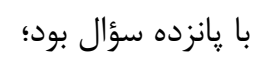

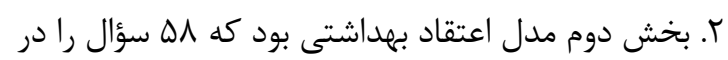

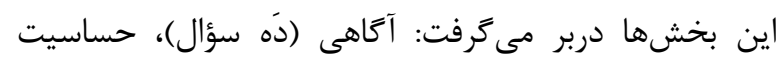

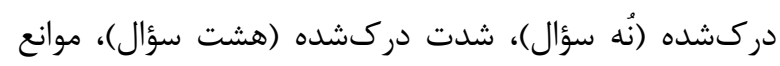

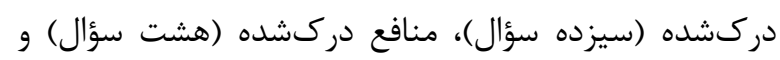

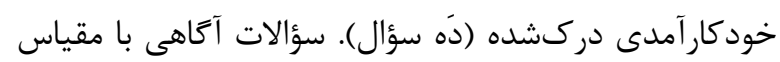

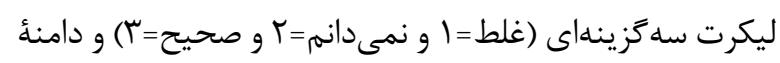

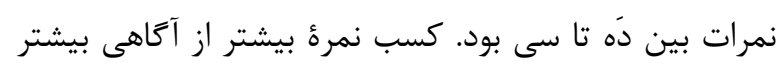

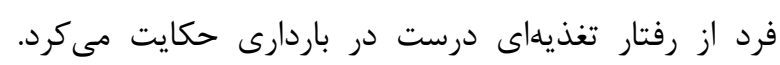

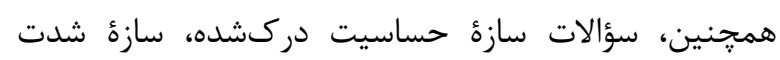

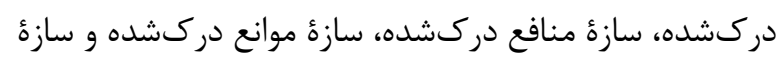

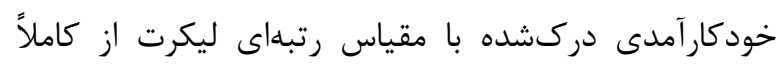

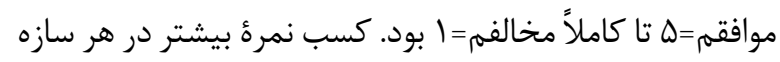
از وضعيت بهتر آن سازه حكايت مى كرد؛
شش سازه دارد: I. حساسيت دركشده؛ ז. منافع دركشده؛

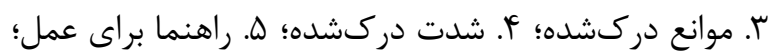

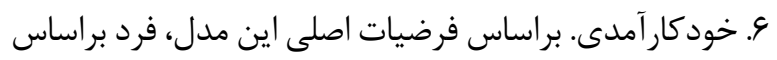

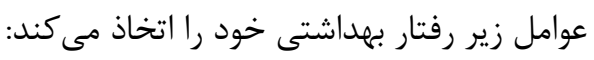
•افزايش حساسيت به ابتلا به بيمارى يا حالتى زئى زيانبار

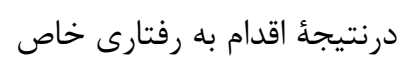

• افزايش ادراك شخص درباره شدت آسيب رِديديدآمده

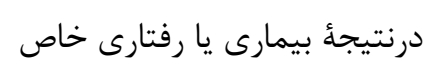

•افزايش درى فرد به منافع حاصل از انجام رفتاص بـار

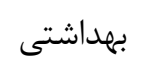

• كاهش مانع ها و هزينهها درنتيجئُ رفتار بهداشتى

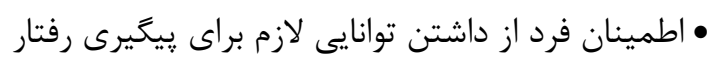

$$
\text { بهداشتى }
$$

• راهنمايى براى تسريع در اتخاذ رفتار بهداشتى [- بهائ

[rq

مدل اعتقاد بهداشتى سعى مىكند آكاهى و نكرش

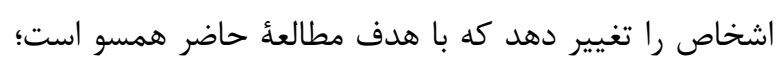

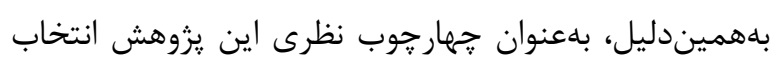

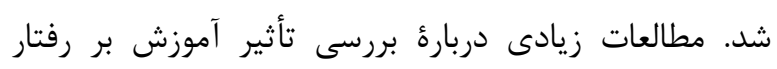

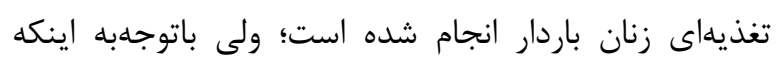

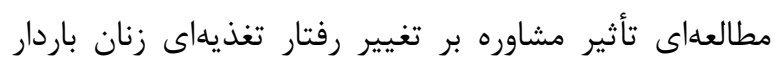

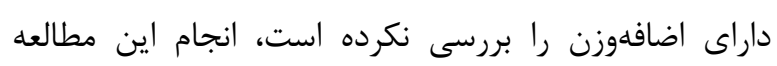

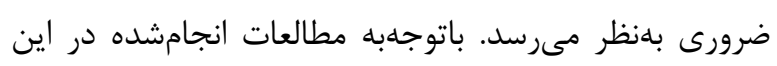

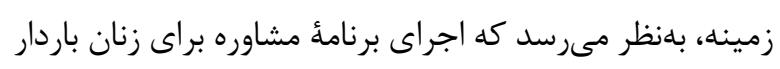

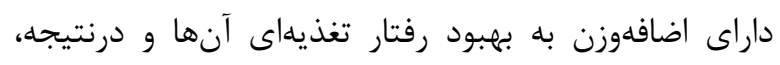

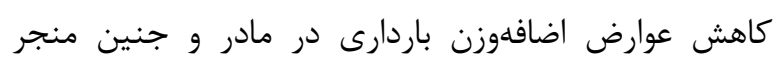

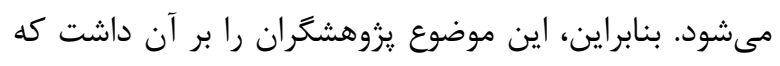

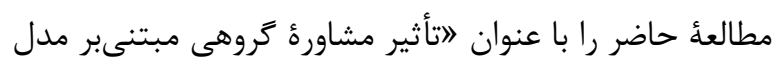

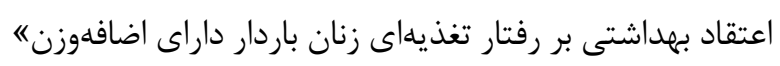

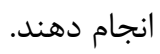

$$
\text { روش كار }
$$

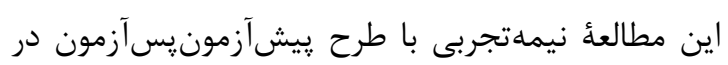

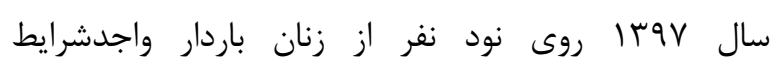

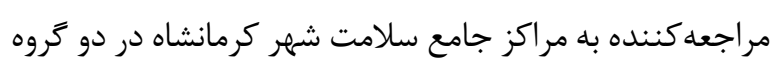

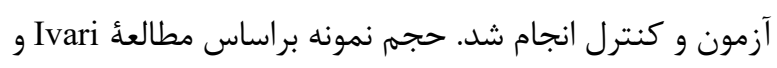

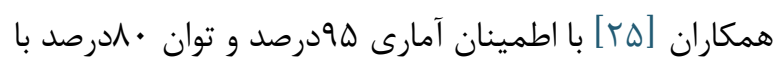

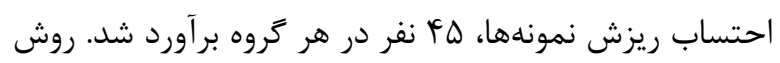


جلسات مشاوره براساس الكَوى اعتقاد بهداشتى شامل

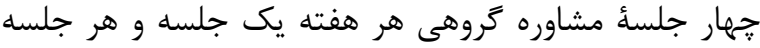

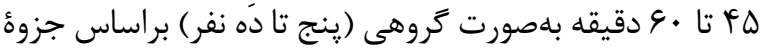
تهيهشده طبق مدل اعتقاد بهداشتى به روش سخنرانى، ارائه تصاوير ازطريق ياوريوينت، بحث تروهى، برسشوياستخ يمفلت و توضيح يوستر هرم غذايى به كمك مشاور تغذيه بركزار

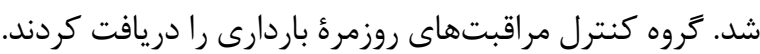

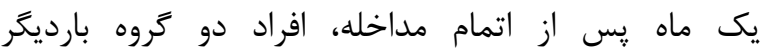
يرسشنامهها را تكميل كردند. دادهها با استفاده از نرمافزار

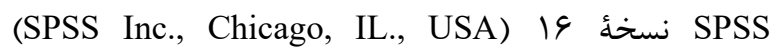
تجزيهوتحليل شدند. براى بررسى طبيعىبودن توزيع دادههاى كمّى، از آزمون كولموكروفاسميرنوف و براى مقايسٔ دو كروه

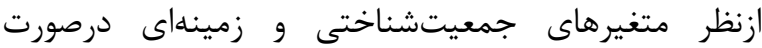

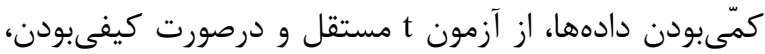
از آزمون كاىدو استفاده شد. افزونبراين، براى بررسى تفاوت آنات بين دو كَروه ازنظر سازههاى مختلف الكَى اعتقاد بهداشتى و رفتار تغذيهاى، از آزمون ANCOVA بهره برده شد. ناكفته نماند سطح معنىدارى در تمامى آزمونهاى آمارى كمتر از

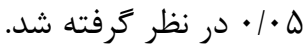

r. بخش سوم بررسى رفتار تغذيهاى شامل צr سؤال رفتارى با مقياس رتبهاى ليكرت ينجتايى از هميشه=ها

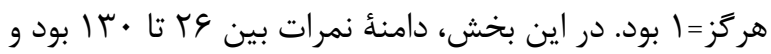
نمرءٔ بيشتر نشاندهنده وضعيت بهتر اين يرسشنامه بود. بلمنظور تهيئ ترسشنامه از راهنماى جامع تغذيه مادران باردار و شيرده استفاده شد. براى بررسى روايى صورى يرسشنامهها تمام سؤالات را سى نفر از مادران شركت كننده برداد

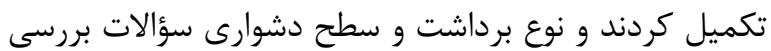
و اصلاحات پيشنهادى اعمال شد. در بررسى روايى محتوايى

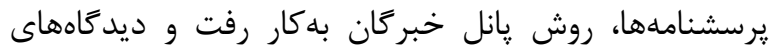

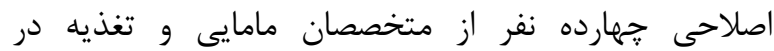
ير سشنامه اعمال و از اين طريق نسبت روايى محتوايى (CVR) وضوح و سادگى و ارتباط سؤالات مرتبط به سازههاى مدل

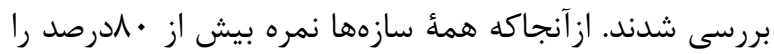

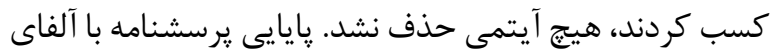

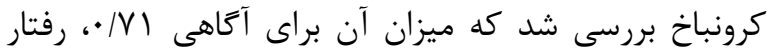

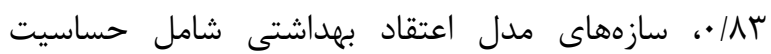
دركشده، شدت دركشده، موانع دركشده، منافع دركشدها

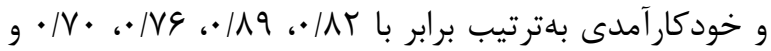

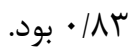

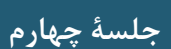

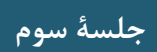

$$
\begin{aligned}
& \text { آشنايى مقدماتى با اصول كلى آشنايى مادران با اضافهوزن و آشنايى مادر با رفتار تغذيهاى مرور مطالب و نتيجهذيرى }
\end{aligned}
$$

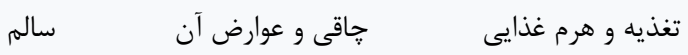

$$
\begin{aligned}
& \text { هدف } \\
& \text { منطبق با مراحل اول و دوم و منطبق با مراحل دوم و سوم ومنطبق با مراحل سوم و منطبق با مرحلة ششم }
\end{aligned}
$$

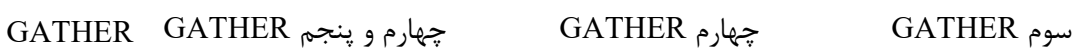

$$
\begin{aligned}
& \text { افزايش خودكارآمدى و رفتار } \\
& \text { تغذيهاي، استفاده از كتابحه } \\
& \text { بعنوان راهنما براى عمل }
\end{aligned}
$$

$$
\text { افزايش حساسيت و شدت افزايش منافع و موانع }
$$

تشريح عوارض و مشكلات جاقى در باردارى بلمنظور

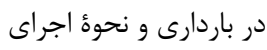

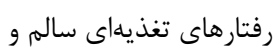

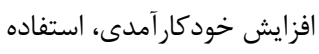

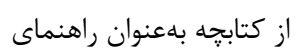

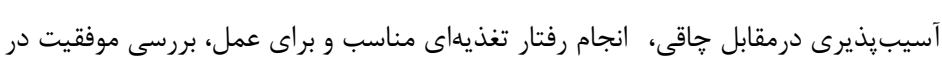

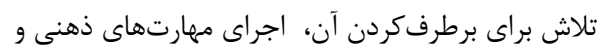

ارائه آمارهاى مربوط به درمابل جافي

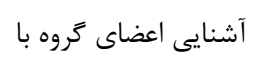
يكديكر، بيان اهداف جلسات مشاوره، فراهم كردن شرايط براى ايجاد روابط و ارتباطات اقدامات مشاورهاى

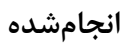
باز، تأكيد بر روابط و يويايى كرو 


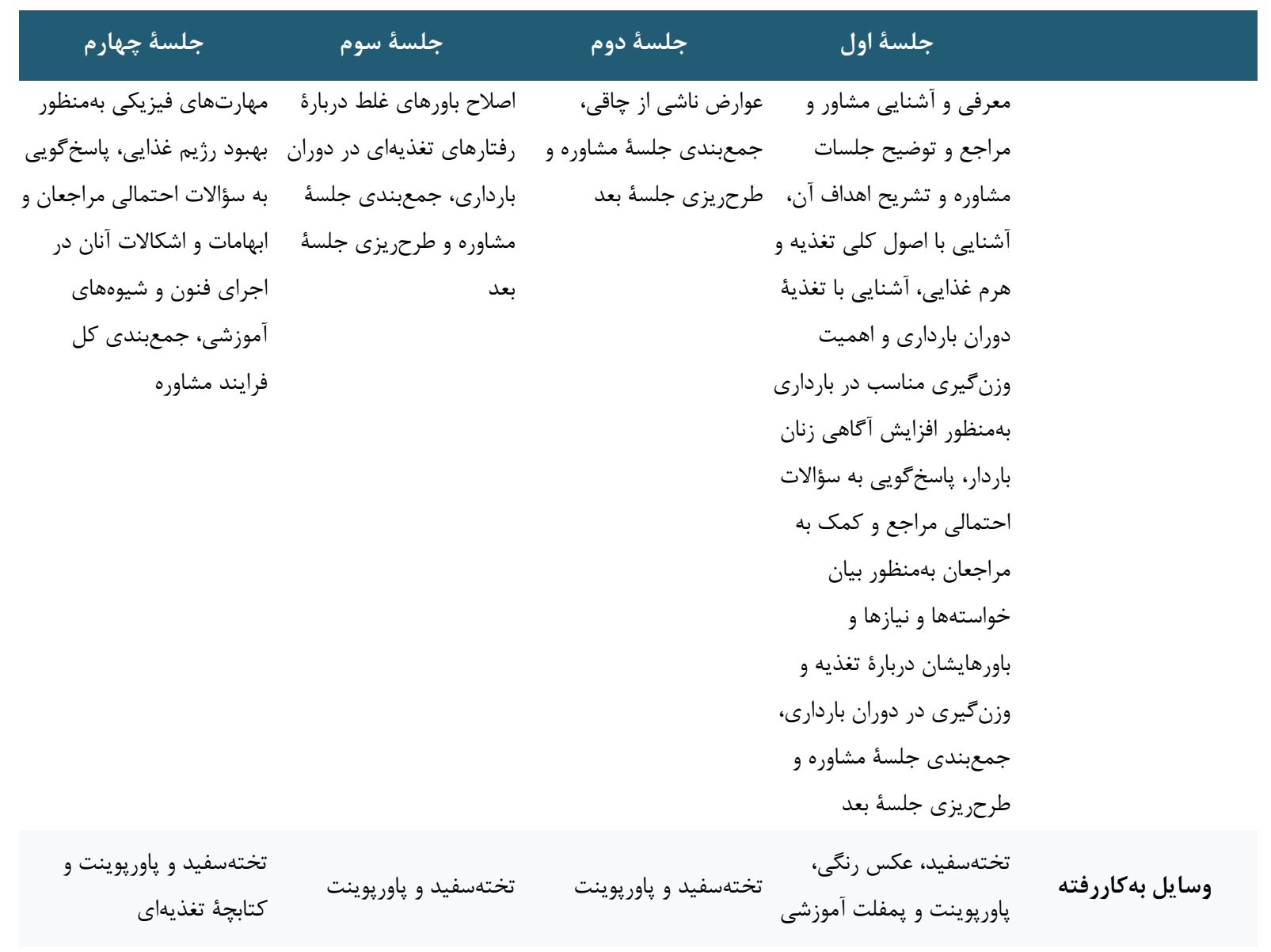

بافته ها

مداخله بلطورمعنادارى بيشتر از گروه كنترل است (بهترتيب

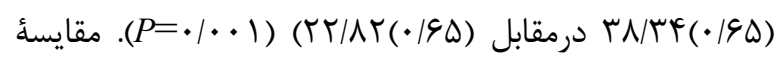
ميانگين نمرات شدت دركشده در مرحله بعد از مداخله نشان مىدهد كه ميانخين نمره شدت دركشده در گروه مداخله

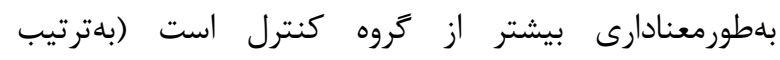
(ه9) ميانگين نمرات منافع دركشده در مرحله بعد از مداخله نشان

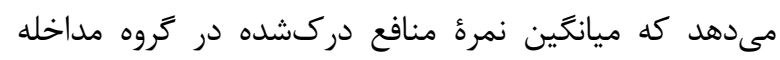

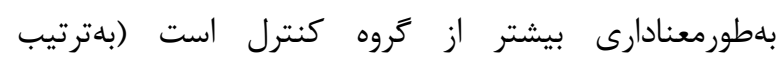

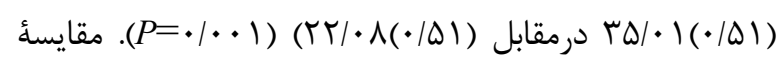
ميانخين نمرات موانع دركشده در مرحلهُ بعد از مداخله نشان

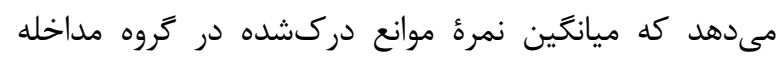

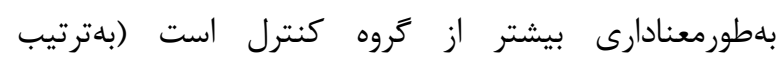
مانs ميانگين نمرات خودكارآمدى در مرحله بعد از مداخله نشان
نتايج نشان داد ميانگين سنى شركت كنندگان در گروه

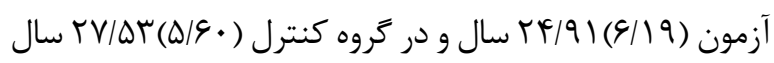
و ميانكين BMI در زروه مداخله بيشتر از زروه كنترل بود

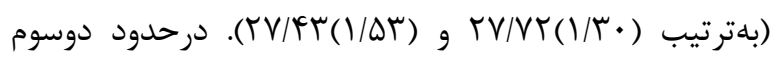
افراد در هر دو گروه يرايمى دييلم و تحصيلات بيشتر همسران در دو گروه زيردييلم بود.

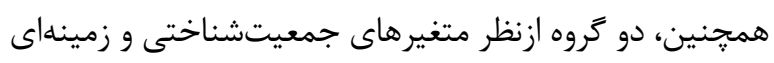
اختلاف آمارى معنادارى نداشتند (جدول (1).

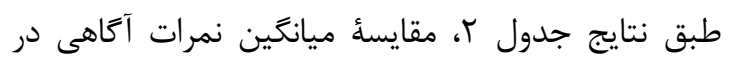

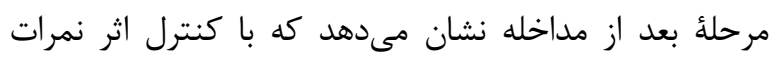

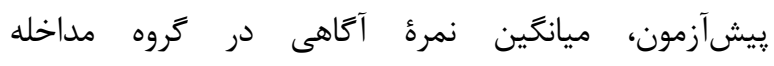

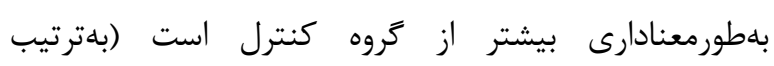

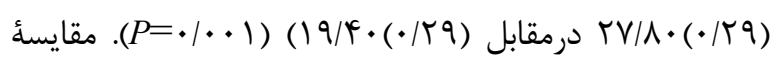
ميانگين نمرات حساسيت دركشده در مرحلة بعد از مداخله نشان مىدهد كه ميانگين نمره حساسيت دركشده در كروه 


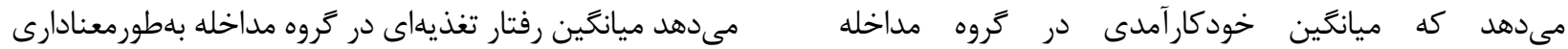

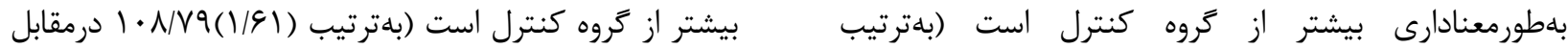

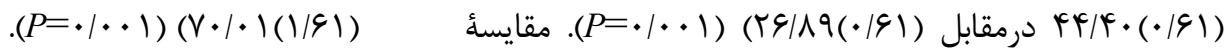

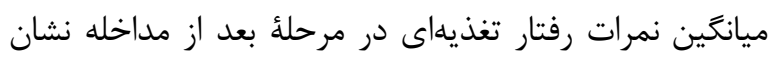

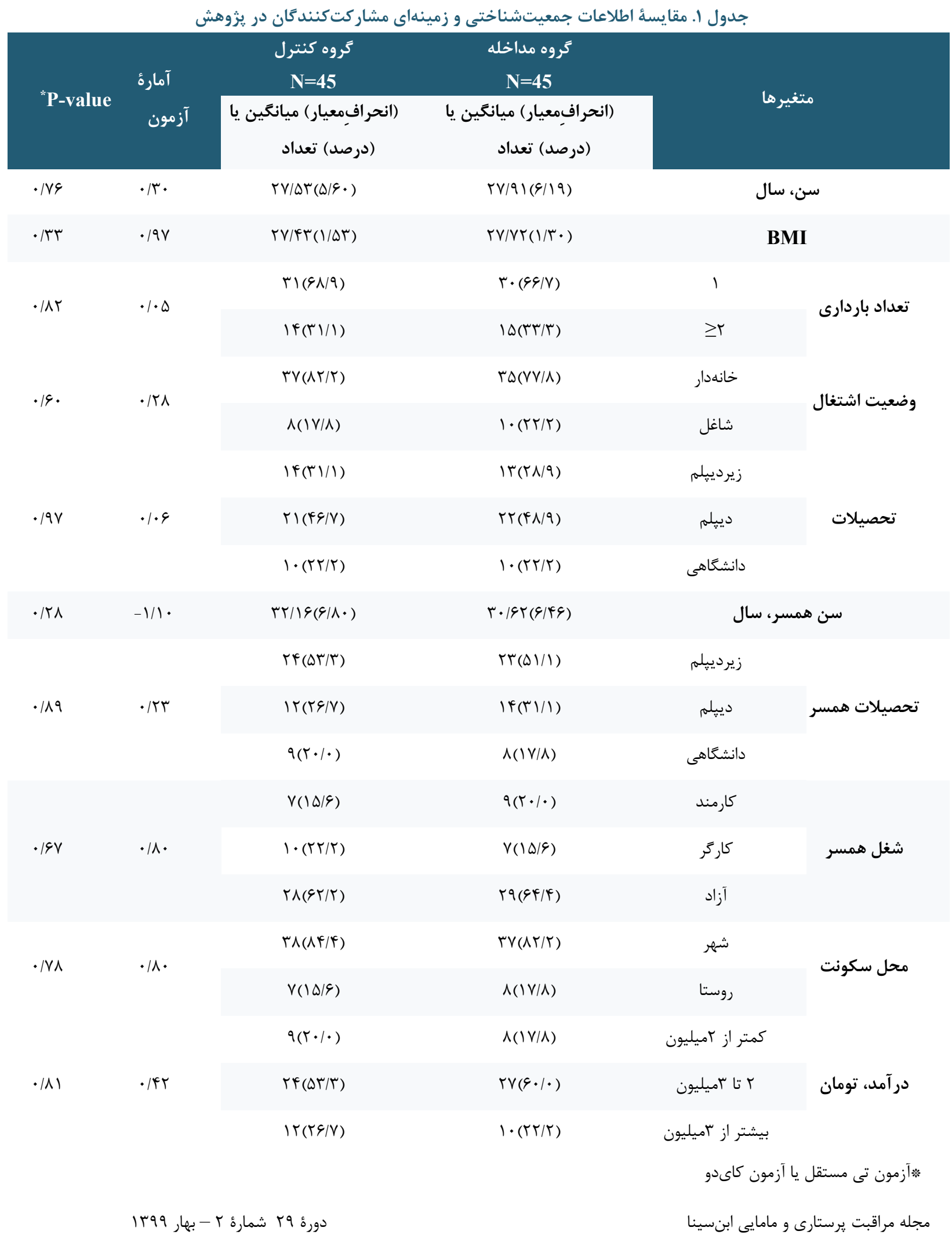


جدول r. نتايج مقايسه نمرات سازههاى مختلف يرسشنامه در دو كروه كنترل و آزمون با كنترل اثر بيش آزمون

\begin{tabular}{|c|c|c|c|c|}
\hline P-value* & $F^{*}$ & $\begin{array}{c}\text { كروه كنترل } \\
\text { Adjusted mean (SD) }\end{array}$ & $\begin{array}{c}\text { كروه مداخله } \\
\text { Adjusted mean (SD) }\end{array}$ & متغير ها \\
\hline$\cdot / \cdot \cdot 1$ & FrQ/Fq & $19 / 4 \cdot(\cdot / / 9)$ & $r V / \Lambda \cdot(\cdot / T q)$ & آتاهى \\
\hline$\cdot 1 \cdot \cdot 1$ & TAY/QT & Tr/AT $(\cdot \mid 9 \Delta)$ & $r \Lambda / \mu \Psi(\cdot \mid 9 \Delta)$ & حساسيت دركشده \\
\hline$\cdot / \cdot 1$ & MIE/Ta & $r \cdot \mid \wedge \Delta(\cdot \mid \Delta \varphi)$ & $r \Delta / / \Delta(\cdot / \Delta \varphi)$ & شدت دركشده \\
\hline$\cdot 1 \cdot \cdot 1$ & rID/rT & $r Y / \cdot \Lambda(\cdot|Q|)$ & $r \Delta / \cdot 1(\cdot|\Delta|)$ & منافع دركشده \\
\hline$\cdot 1 \cdot \cdot 1$ & $\mathrm{rt} \cdot / 1 \mathrm{q}$ & $T \Delta / \& T(\cdot \mid \Lambda F)$ & $\Delta \varepsilon / 9 \Lambda(\cdot / \Lambda F)$ & موانع دركشده \\
\hline$\cdot / \cdot \cdot 1$ & $f \cdot N / I F$ & r $9 / 19(\cdot|9|)$ & $f F / F \cdot(\cdot|q|)$ & خودكار آمدى \\
\hline$\cdot 1 \cdot \cdot 1$ & $\Gamma \wedge \Delta / \Delta \varphi$ & $V \cdot / \cdot 1(1 / 91)$ & $1 \cdot 1 / \vee 9(1 / 91)$ & رفتار تغذيهاى \\
\hline
\end{tabular}

*ANOVA/ANCOVA

مطالعات نيز نشاندهنده تأثير مثبت مداخلات آموزشى بر

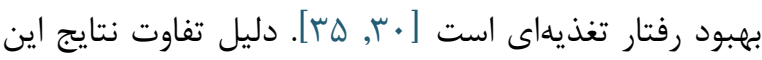

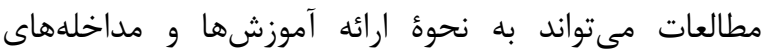
آموزشى مربوط باشد. شايان ذكر است بايد به اين نكته نيز توجه كنيم كه آكاهى

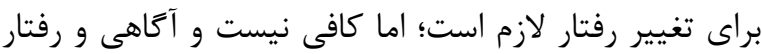

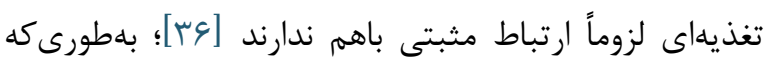

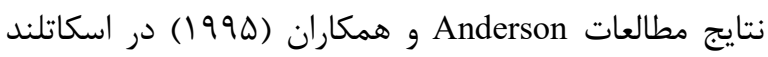

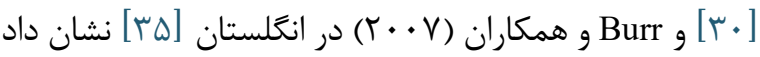

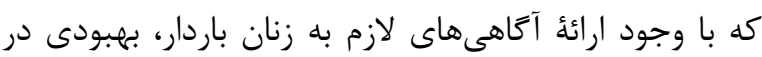
رفتارهاى تغذيهاى آنان مشاهده نشد. نبود تأثير مثبت بأن معنادار

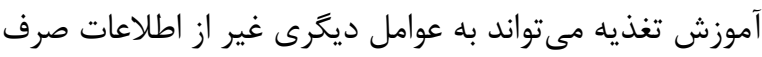

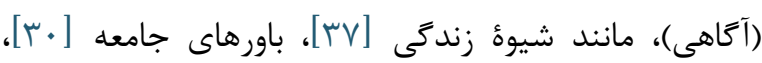

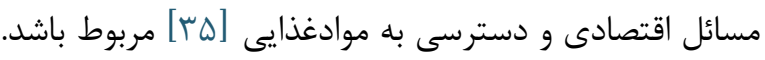

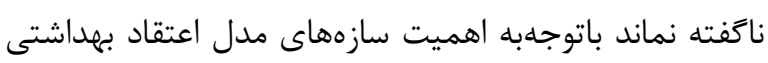

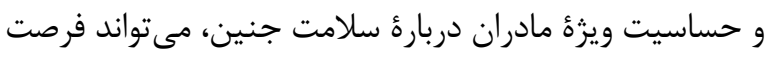
مناسبى براى آموزش هاى مؤثرتر و كارآمدتر آنان دان ايجاد آناد كند. آنجه در اين قسمت اهميت دارد، افزايش حساسيت، شدرت

دركشده، شناخت موانع دركشده و منافع دركشده در دران

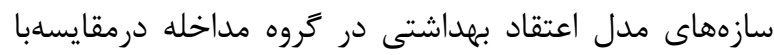

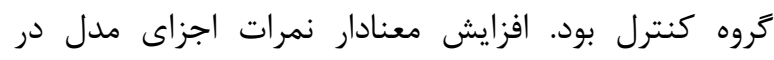

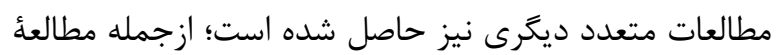
Sharifirad
براساس يافتههاى حاصل از يزوهش حاضر، آكاهى و رفتار

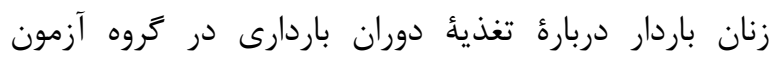

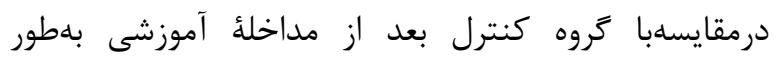

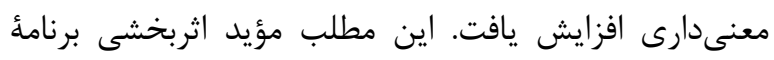

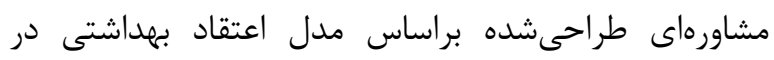

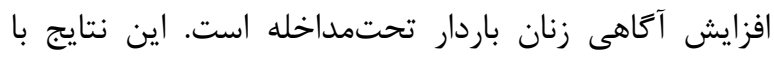

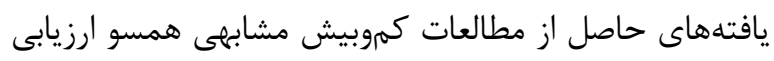

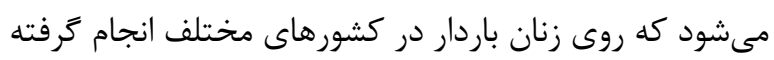

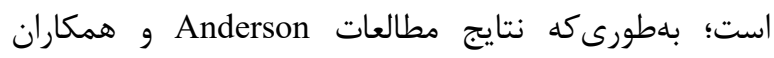

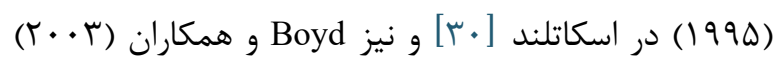

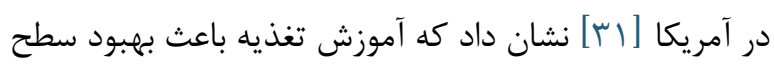

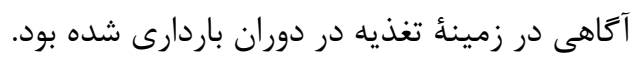

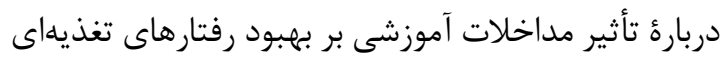
زنان باردار نيز برخى از مطالعات نتايج مشابهى نشاتى نشان دادئ دادند.

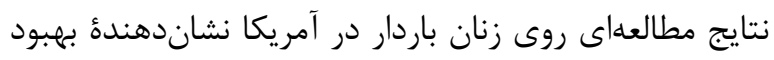

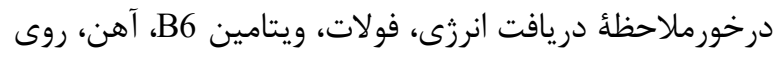

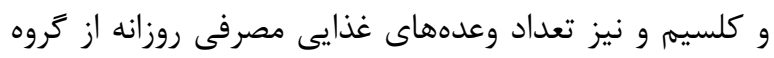

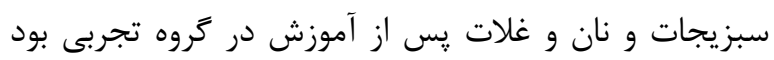

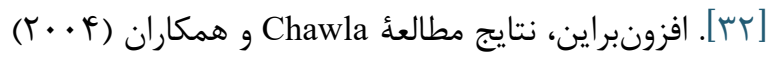

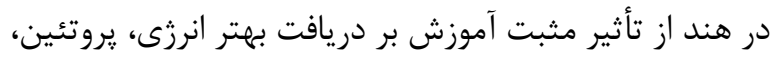

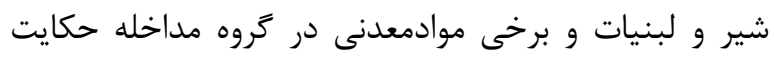

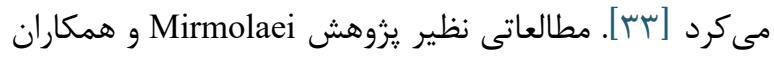

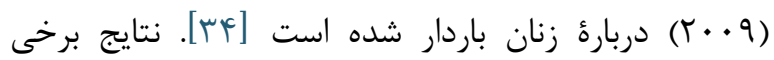


موجود براى اصلاح تغذيه و درنتيجه ارتقاى رفتار صحيح

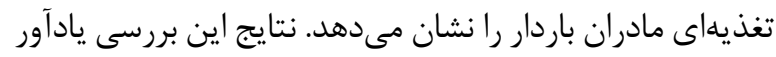

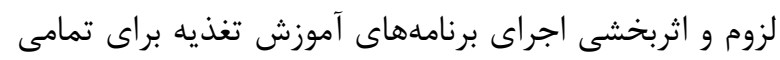

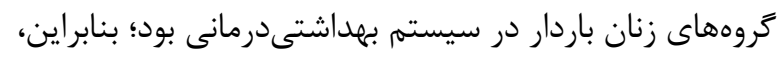

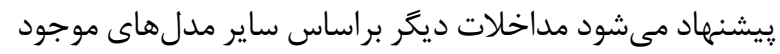

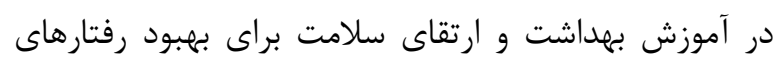

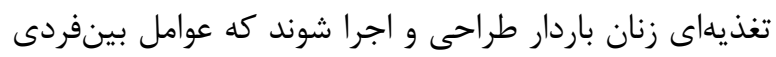

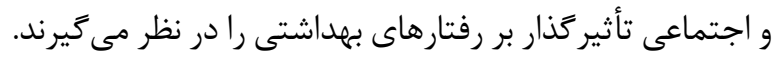

\section{سياسگزارى}

اين مقاله بركرفته از ياياننامئ مصوّب در دانشكده علوم

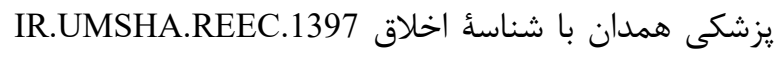

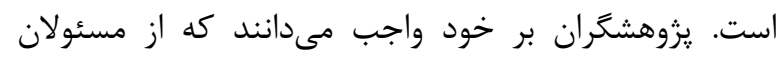

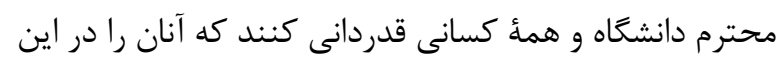
طرح تحقيقاتى يارى كردهاند.

$$
\text { تعارض در منافع }
$$

بين نويسندكان هيجگَّنه تعارضى در منافع وجود ندارد

$$
\text { منابع مالى }
$$

منابع مالى اين مطالعه توسط نويسندكان تامين شده است.

\section{References}

1. Safari M, Saadatmand N, Azarman M. Food intake pattern and related factors in women referred to medical and health centers of Yasouj-2006. Dena. 2007; 2(2): 27-37.

2. Szwajcer EM, Hiddink GJ, Koelen MA, van Woerkum CM. Nutrition awareness and pregnancy: Implications for the life course perspective. Eur J Obstet Gynecol Reprod Biol. 2007; 135(1): 58-64. [DOI:10.1016/i.ejogrb.2006.11.012] [PMID]

3. Abrams B, Altman SL, Pickett KE. Pregnancy weight gain: Still controversial. Am J Clinl Nutr. 2000; 71(5): 1233S-41S. [DOI:10.1093/ajen/71.5.1233s] [PMID]

4. Siega-Riz AM, Evenson KR, Dole N. Pregnancyrelated weight gain--a link to obesity? Nutr Rev. 2004; 62(7 Pt 2): S105-11. [DOI:10.1301/nr.2004.jul.S105S111]

5. Brynhildsen J, Sydsjö A, Norinder E, Selling KE, Sydsjö G. Trends in body mass index during early pregnancy in Swedish women 1978-2001. Public Health. 2006; 120(5): 393-99. [DOI:10.1016/i.puhe.2005.10.015] [PMID]

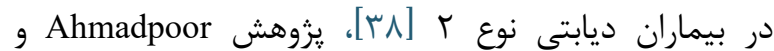

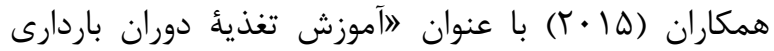
براساس مدل اعتقاد بهداشتى"، تحقيق Sharifirad و همكاران

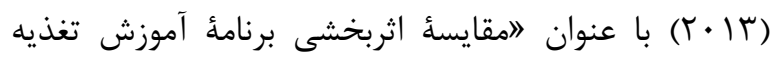
براساس مدل اعتقاد بهداشتى با آموزش سنتى در افزايش وزن

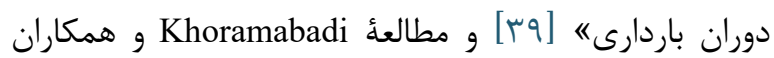

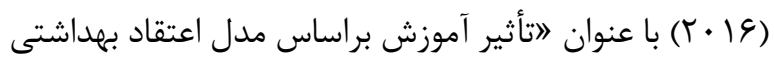

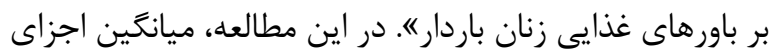

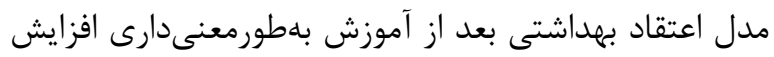

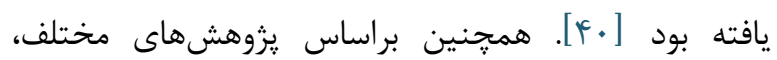
افزايش حساسيت و شدت دركشده از عوامل پيشبينى كننده در اتخاذهاى مناسب بهداشتى محسوب مىشود. بنابراين، مطلب گوياى واقعيتى است كه ارائٔ آموزشىهاى لازم به زنان باردار را براى قبول منافع ناشى از تغذيه مناسب و غلبه بر

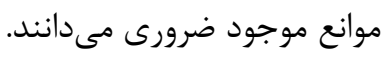

$$
\text { نتيجه كَيرى }
$$

نتايج حاصل از اين يزوهش اثربخشى برنامئ آموزشى

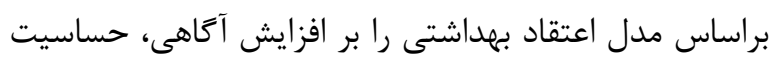
دركشده، شدت دركشده، منافع دركشده و كاهش موانع

6. Buxton BK, Snethen J. Obese women's perceptions and experiences of healthcare and primary care providers: A phenomenological study. Nurs Res. 2013; 62(4): 252-59. [DOI:10.1097/NNR.0b013e318299a6ba] [PMID]

7. McGiveron A, Foster S, Pearce J, Taylor MA, McMullen S, Langley-Evans SC. Limiting antenatal weight gain improves maternal health outcomes in severely obese pregnant women: Findings of a pragmatic evaluation of a midwife-led intervention. $\mathrm{J}$ Hum Nutr Diet. 2015; 28(Suppl 1): 29-37. [DOI:10.1111/ihn.12240] [PMID]

8. Ahmadzadeh Sani T, Peyman N, Esmaeili H. The relationship between obesity and complications duing pregnancy and childbirth in dargaz: A cross sectional study. J North Khorasan Uni Med Sci. 2016; 8(3): 383-93. [DOI:10.18869/acadpub.jnkums.8.3.383]

9. Engin A. The definition and prevalence of obesity and metabolic syndrome. Adv Exp Med Biol. 2017; 960: 1-17. [DOI:10.1007/978-3-319-48382-5 1] [PMID] 
10. Azizi F, Azadbakht L, Mirmiran P. Trends in overweight, obesity and central fat accumulation among Tehranian adults between 1998-1999 and 2001-2002: Tehran lipid and glucose study. Ann Nutr Metab. 2005; 49(1): 3-8. [DOI:10.1159/000084171] [PMID]

11. Prentice AM. The emerging epidemic of obesity in developing countries. Int J Epidemiol. 2006; 35(1): 93-99. [DOI:10.1093/ije/dyi272] [PMID]

12. Bakouei F, Jalalmanesh S. Relationship between maternal obesity and pregnancy outcome. J Babol Uni Med Sci. 2001; 3(11): 21-25.

13. Moos MK, Dunlop AL, Jack BW, Nelson L, Coonrod DV, Long R, et al. Healthier women, healthier reproductive outcomes: Recommendations for the routine care of all women of reproductive age. Am J Obstet Gynecol. 2008; 199(6 Suppl 2): S280-S9. [DOI:10.1016/j.ajog.2008.08.060] [PMID]

14. Panahandeh Z, Pour Ghasemi M, Asgharnia M. Body mass index and prenatal weight gain. J Guilan Uni Med Sci. 2006; 15(57): 15-20.

15. Guelinckx I, Devlieger R, Beckers K, Vansant G. Maternal obesity: Pregnancy complications, gestational weight gain and nutrition. Obes Rev. 2008; 9(2): $\quad 140-50$ 789X.2007.00464.x] [PMID]

[DOI:10.1111/j.1467-

16. Vizeshfar F, Sharifzadeh Z. Assessment body mass index effect on pregnancy outcomes in Larian women referred to health center in 2008. Iran J Obstet Gynecol Infertil. 2011; 14(4): 41-6.

17. Mostafa Garebagi P. Evaluation the effect of excessive maternal weight on pregnancy outcome. Iran J Obstet Gynecol Infertil. 2001; 10(4): 36-41.

18. Darnton-Hill I, Nishida C, James W. A life course approach to diet, nutrition and the prevention of chronic diseases. Public Health Nutr. 2004; 7(1a): 101-21. [DOI:10.1079/PHN2003584] [PMID]

19. Denison F, Price J, Graham C, Wild S, Liston W. Maternal obesity, length of gestation, risk of postdates pregnancy and spontaneous onset of labour at term. Int J Obstet Gynaecol. 2008; 115(6): 720-5. [DOI:10.1111/j.1471-0528.2008.01694.x] [PMID] [PMCID]

20. Phelan S. Pregnancy: A "teachable moment" for weight control and obesity prevention. Am J Obstet Gynecol. 2010; 202(2): 135.e1-e8 [DOI:10.1016/j.ajog.2009.06.008] [PMID] [PMCID]

21. Mansurian M, Soleymaninejad M, Behnam Pour N. The effects of educational interventions on knowledge and attitude of pregnant women towards nutrition during pregnancy. J Uni Med Sci Lorestan. 2011; 1(1): $1-8$.

22. Zhang CH, Liu XY, Zhan YW, Zhang L, Huang YJ, Zhou H. Effects of prepregnancy body mass index and gestational weight gain on pregnancy outcomes. Asia Pac J Public Health. 2015; 27(6): 620-30. [DOI:10.1177/1010539515589810] [PMID]
23. Tabandeh A, Kashani E. Effects of maternal body mass index and weight gain during pregnancy on the outcome of delivery. J Gorgan Uni Med Sic. 2007; 9(1): 20-24.

24. Ivari TK, Heshmati H, Faryabi R, Goudarzian Z, Ghodrati A, Najafi F, et al. Effect of health belief model based education on nutritional behaviors of pregnant women referred to health centers in Torbate-heydariyeh city. J Health Field. 2016; 3(4): 22-31.

25. Ahmadpoor H, Maheri A, Shojaizadeh D. Effectiveness of nutrition education based on health belief model during pregnancy on knowledge and attitude of women referred to Health Centers of Gonbad Kavoos city. J Neyshabur Uni Med Sci. 2015; 3(2): 52-60.

26. Ziaee R, Jalili Z, Tavakoli GH. The effect of education based on Health Belief Model (HBM) in improving nutritional behaviors of pregnant women. J North Khorasan Uni Med Sci. 2016; 8(3): 427-37. [DOI:10.18869/acadpub.jnkums.8.3.427]

27. Tol A, Majlesi F, Shojaeizadeh D, Esmaelee Shahmirzadi S, Mahmoudi Majdabadi M, Moradian $M$. Effect of the educational intervention based on the health belief model on the continuation of breastfeeding behavior. J Nurs Educ. 2013; 2(2): 3947.

28. Mosayebi M, Zamani F, Khazaii MR. The effect of education based on a health belief model on Giardia Lamblia preventive behaviors of primary school students in Arak. Arak Med Uni J. 2011; 14(3): 64-72.

29. Anderson AS, Campbell DM, Shepherd R. The influence of dietary advice on nutrient intake during pregnancy. $\mathrm{Br} \mathrm{J}$ Nutr. 1995; 73(2): 163-77. [DOI:10.1079/BJN19950021] [PMID]

30. Boyd NR, Windsor RA. A formative evaluation in maternal and child health practice: the partners for life nutrition education program for pregnant women. Matern Child Health J. 2003; 7(2): 137-43. [DOI:10.1023/A:1023873112024] [PMID]

31. Widga AC, Lewis NM. Defined, in-home, prenatal nutrition intervention for low-income women. J Am Diet Assoc. 1999; 99(9): 1058-62. [DOI:10.1016/S0002-8223(99)00251-5]

32. Chawla PK, Kaur R, Sachdeva R. Impact of nutrition counselling on food and nutrient intake and haematological profile of rural pregnant women. J Hum Ecol. 2004; 15(1): 51-5. [DOI:10.1080/09709274.2004.11905666]

33. Mirmolaei S, Moshrefi M, Kazemnejad A, Farivar F, Morteza $\mathrm{H}$. The effect of nutrition education on nutritional behaviors in pregnant women. Hayat. 2009; 15(4): 35-42.

34. Burr M, Trembeth J, Jones K, Geen J, Lynch L, Roberts $Z$. The effects of dietary advice and vouchers on the intake of fruit and fruit juice by pregnant women in a deprived area: A controlled trial. Public Health Nutr. 2007; 10(6): 559-65. [DOI:10.1017/S1368980007249730] [PMID] 
35. Gilkey MB, Earp JAL, French EA. Applying health education theory to patient safety programs: three case studies. Health Promot Pract. 2008; 9(2): 123-9. [DOI:10.1177/1524839907312703] [PMID]

36. Vameghi R, Mohammad K, Karimloo M, Soleimani F, Sajedi F. The effects of health education through face to face teaching and educational movies, on suburban women in childbearing age. Iran J Public Health. 2010; 39(2): 77-88.

37. Sharifirad G, Entezari MH, Kamran A, Azadbakht L. The effectiveness of nutritional education on the knowledge of diabetic patients using the health belief model. J Res Med Sci. 2009; 14(1): 1-6.

38. Ahmadpoor H, Maheri A, Shojaizadeh D. Effectiveness of nutrition education based on health belief model during pregnancy on knowledge and attitude of women referred to health centers of Gonbad Kavoos city. J Neyshabur Univ Med Sci. 2015; 3(2): 52-60.

39. Sharifirad GR, Tol A, Mohebi S, Matlabi M, Shahnazi $\mathrm{H}$, Shahsiah M. The effectiveness of nutrition education program based on health belief model compared with traditional training. J Educ Health Promot. 2013; 2: $15 . \quad$ [DOI:10.4103/2277-
[DO 9531.112684] [PMID] [PMCID]

40. Khoramabadi M, Dolatian M, Hajian S, Zamanian M, Taheripanah R, Sheikhan Z, et al. Effects of education based on health belief model on dietary behaviors of Iranian pregnant women. Glob J Health Sci. 2016; 8(2): 230-9. [DOI:10.5539/gjhs.v8n2p230] [PMID] [PMCID] 